\title{
A IRONIA DO DIÁRIO ÍNTIMO NA POESIA DE ADÍLIA LOPES
}

\author{
Lúcia Evangelista ${ }^{1}$
}

RESUMO: Adotando formulações típicas de gêneros autobiográficos, Adilia Lopes traz para o interior da poesia a ideia de veracidade simulada por esses gêneros. Dessa forma, desloca o lugar do sujeito lírico que aparece estranhamente vinculado à figuração de uma personalidade, mas sem deixar de se afirmar como produto do texto.

PALAVRAS-CHAVE: Diário; Poesia; Ironia

ABSTRACT: Adopting typical formulations of autobiographical genres, Adilia Lopes brings the idea of truthfulness simulated by these genres inside the poetry. Thus, moving the place of the lyrical subject that appears strangely linked to the figuration of a personality, but without leaving to assert itself as a product of the text.

KEYWO RDS: Diary; poetry; irony

Escrever é uma questão de devir, sempre inacabado, sempre a fazer-se, que extravasa toda a matéria vivivel ou vivida. É um processo, quer dizer, uma passagem de Vida que atravessa o viwivel e o vivido."

(Gilles Deleuze, Crítica e Clínica, 1997, p. 11)

O poema: "A poesia de cada dia/ nos dai hoje" (LOPES, 2010, p. 23) aparece no penúltimo livro de Adília Lopes, Apanhar ar. Um livro tímido - de pouco mais de vinte páginas - no qual os poemas não ultrapassam muito em tamanho este que transcrevemos acima. São centelhas de vida convertidas em verso. Registros de coisas cada vez mais mínimas: “À noite/ com a iluminação pública/ as sombras dos choupos/ nas cortinas das janelas/ da minha sala" (ibidem, p. 9); "A minha varanda velha/ com quatro gerânios velhos" (ibidem, p. 14); “Chego cedo ao café/ à hora a que estão a entrar/ as batatas e as cebolas/ os legumes dão-me paz" (ibidem, p. 18).

Nesse direcionamento para o cada vez menor - quase em formato de haikai - a vocação de Adília para o olhar sobre o cotidiano irá, cada vez mais, se converter em uma poesia do instante. "O mais poético porque mais prosaico", postulado por Adília, se intensifica, carregando de lirismo esses microrretratos do banal.

Os poemas de Adília Lopes se deslocam da rua para a casa, do público para o íntimo contaminando reciprocamente o público e o privado. A poetisa abre uma fresta para que mundo e intimidade se conjuguem no limite de um espaço entre o interior e o exterior: "Café/ lugar que é rua/ e casa” (LOPES, 2010, p.20).

Escreveu Adília em um livro anterior: "a poetisa é a mulher-a-dias/ arruma o poema/ como

\footnotetext{
1 Mestrado em Estudos Literários, Culturais e Interartes no Ramo de Literatura Portuguesa da Faculdade de Letras da Universidade do Porto - Portugal. Estudante Colaborador do Aesthetics, Politics and Arts Group do Instituto de Filosofia da Faculdade de Letras da Universidade do Porto - Portugal.
} 
arruma a casa/ que o terremoto ameaça/ a entropia de cada dia/ nos dai hoje/ o pó e o amor/ como o poema/ são feitos/ no dia a dia” (LOPES, 2002, p. 447). Rezar para que a poesia não falte é o mesmo que rezar para que não faltem os dias; uma está em função dos outros. Pede-se aos dias que se convertam e se transformem em escrita. "Aquele que nada faz de sua vida escreve que não faz nada, e eis, apesar de tudo, algo de feito. Aquele que se deixa desviar da escrita pelas futilidades do dia agarra-se a esses nadas para contá-los, denunciá-los ou gozá-los, e eis um dia preenchido”, disse Blanchot (2005, p. 274) acerca do diário íntimo². Nas palavras de Adília: "Perco-me/ no labirinto/ dos dias// Ganhome/ no labirinto/ dos dias// A poesia/ é o perde-ganha// E o labirinto/ dos dias/ é o labirinto/ dos dias" (LOPES, 2004, p. 583). O cotidiano é poema, mas o poema é também cotidiano - no perdeganha entre um e outro, o sujeito se deixa perder nos labirintos da linguagem.

A "autobiografia" adiliana refere-se a um nome e a uma personalidade criados. (O nome civil da autora é Maria José Fidalgo Viana ${ }^{3}$. Por sua vez, o "diário" adiliano refere-se a um deslindar de instantes escritos ${ }^{4}$. Logo, o tempo e o sujeito que se "contam" ganham outras reverberações 5 .

\title{
FIM DE TARDE EM LISBOA
}

\author{
O meu quarto \\ é um aquário \\ e eu um peixe \\ para o choupo \\ que me vê \\ do outro lado \\ dos vidros \\ da janela
}

As sombras

do choupo

e o Sol

\footnotetext{
2 No início do texto de Maurice Blanchot a que nos referimos, “O Diário Íntimo e a Narrativa”, o autor sobreporá a narrativa ao diário íntimo por essa "rasgar o tecido dos acontecimentos" (BLANCHOT, 2005, p. 272), enquanto o diário seria "uma maneira cômoda de escapar do silên cio, como ao que há de extremo na fala" (ibidem, p. 273). Porém, Blan chot sublinhará que quando o diário volta-se para o interior da es crita, quando aqueles que o escreveram e "reconhecem pou co a pouco que não podem conhecer-se, mas somente transformar-se e destruir-se, e que pross eguem nesse estranho combate que os atrai para fora deles mesmo, num lugar ao qual não têm acesso, deixaram-nos, segundo suas forças, fragmentos, aliás por vezes impessoais, que podemos preferir à qualquer obra” (ibidem, p. 277).

${ }^{3}$ Em relação à criação de seu pseudônimo, Adília Lopes conta numa entrevista: “Ora, eu precisava de ter uma pseudônimo e o Miguel Tamen inventou Adília Lopes e Venceslau Passinhas. Eu achei Venceslau Passinhas muito ridículo e era um nome de homem, eu não queria, portanto, ficou Adília Lopes que era de mulher. O Miguel nunca me quis dizer porque é que tinha inventado esse nome, mas uma vez eu estava a falar com um senhor no Centro de Arte Moderna que era advogado e que me disse estar conven cido que Adília Lopes tinha sido uma lançadora de pesos do Sporting e também campeã olímpica ou tinha ido aos jogos olímpicos, já não sei. Realmente no José Pedro Machado em "Adília", vem uma Adília Silvério, que era atleta. (LOPES, 2001, 7)

${ }_{4}^{4}$ Percebemos a presença dessa poesia do instante, especialmente, em três livros recentes da autora - Le vitrail la nuit * $A$ Árvore cortada (2006), Caderno (2007) e Apanhar ar (2010). Em Namorados pobres, Dobra (2009), os poemas seguem a linha mais narrativa/romanesca de Adília.

${ }^{5}$ A cerca disso, Abel Barros Baptista já havia conduído, em ensaio que trabalha as particularidad es da crônica e do diário, que "o diário é in capaz de fazer regressar o nome ao portador do nome, é in capaz de reintegrar na personalidade do autor os elementos dispersos do seu nome e de lhe recompor a identidade - o diário não é senão outra forma de relançar o nome numa fortuna imprevista e in controlável” (BAPTISTA, 2003, p. 46).
} 
de Junho
são mãos
a dizer-me
adeus
A luz
e o rumor
do vento
nos choupos
são borboletas
brancas
É feriado
10 de junho
e Corpo de Deus

Vou ler

Portugal, o Mediterrâneo e o Atlântico

de Orlando Ribeiro

acabei de ler

Não matem o bebé

de Kenzaburo Oé

São $18 \mathrm{~h} 18$

estão $26^{\circ} \mathrm{C}$

no meu quarto

Já começou

a refrescar

De manhã

em Santa Isabel

foi dia

de primeiras comunhões

Calhou-me

quase uma migalha

de hóstia

havia

muita gente (LOPES, 2004, p. 557)

No poema, a imagem do sujeito nos é oferecida de forma completamente indireta. Para começar, é dada por um choupo que vê o sujeito através da janela - e o choupo o vê como um peixe. O sujeito perde a centralidade: coloca-se à mercê do olhar de uma planta que o vê como um animal. E o que fica do momento que esse sujeito se põe a contar é igualmente difuso: um fim da tarde, "a luz e o rumor do vento", os livros lidos. Há, é certo, uma data precisa, vinculada à comemoração da celebração católica do Corpus Christi, data que marca o culto da transformação do pão e do vinho em corpo e sangue de Cristo. Mas, para a poetisa, só restam as migalhas das hóstias: os fragmentos do comum, e da conversão desse comum em revelação (o pão é corpo do filho de Deus), com os quais ela comunga (como fosse a primeira vez) e escreve o poema. O que são detalhadamente descritas são coisas "demasiado pequenas" - as condições do clima, o título e os autores dos livros, a hora e os minutos -, 
mas que acabam por se transmutar em coisas "demasiado grandes" para o sujeito que se deixa ser atravessado por essas coisas. Se ficamos sabendo de algo a respeito desse sujeito será de forma completamente indireta - através dos fragmentos que ele nos oferece e que compõem a "protagonista" do poema.

Em paralelo ao texto acima, lemos, no trecho introdutório de Adília em entrevista para a Revista Inimigo rumor, no 10 :

Estou a responder por escrito a esta entrevista. É domingo de Ramos. Dia 8 de Abril de 2001. Estou no meu quarto. Em Lisboa. Vou responder primeiro à mão e só depois passo, digito, para a disquete. O papel é cor-de-rosa reciclado. E a caneta é verdealface, feita no Japão. (LOPES, 2001, p.18)

Os temas e os esquemas textuais do poema e da declaração relacionam-se entre si. São tão exatos, precisos e pormenorizados que inevitavelmente passamos a os julgar por um critério de verdade. Juntos, moldam a personagem Adília Lopes: mulher, residente em Lisboa, católica e de gostos kitsch.

Podemos, assim, notar nesta poesia uma catábase do poético, que passa por uma concreção extrema do sujeito lírico. Ainda que textual, o sujeito adiliano - através de um complexo detalhamento das suas características físicas, emocionais e contextuais - traz, em si, a possibilidade de ser dimensionado como "pessoa real" e, mais longe ainda, como pessoa comum. Adotando formulações típicas dos gêneros autobiográficos, Adília Lopes traz para o interior da poesia a ideia de veracidade simulada por esses gêneros. Dessa forma, desloca o lugar do sujeito lírico que aparece estranhamente vinculado à figuração de uma personalidade, mas sem deixar de se afirmar como produto do texto.

Ao apropriar-se dessas narrativas da "personalidade", a poesia adiliana desvirtua, pois, o lugar privilegiado e autônomo do poético na tradição da modernidade estética. Ao sugerir a ideia de que seus textos derivam de anotações pessoais, a poetisa põe ainda em jogo as questões do público e do privado, da confessionalidade e da relação com o ínfimo do cotidiano. Mais: convoca o poema como objeto sempre a se fazer - como incompletude, fragmento. Pois, conforme sugere Abel Barros Baptista, a anotação no diário a cada dia "é insignificante, não porque o seja necessariamente em si mesmo enquanto acontecimento ou rotina da vida quotidiana, mas porque fora submetida ao calendário lhe recusa a posteridade de sentido" (BAPTISTA, 2003, p. 33). Vamos adiante no texto:

Então, o sentido do calendário dá aos diários uma de duas únicas justificações: ou a que se estriba na ilusão da notação imediata, da coincidência plena e actual entre o acontecimento e a escrita do acontecimento, que anularia a representação e consequentemente reforçaria a autenticidade do diário; ou a que recolhe dele apenas a fragmentação como forma de resistência à retórica do desenvolvimento; à totalização da obra, à ilusão da arquitetura como veículo privilegiado do sentido e da verdade. (Ibidem)

Percebemos, na obra de Adília Lopes, uma vertente diarística, na medida em que, essa poesia simulará uma escrita reflexiva do instante e de apreensão do ínfimo e do vulgar. Além disso, os livros adilianos simularão a sequencialidade do cotidiano - e as modificações de personalidade no decorrer 
dos anos - de uma vida particular. Um exemplo especial da maneira como Adília Lopes trabalha com a estrutura do diário íntimo pode ser visto no poema "Diário lisboeta", publicado no Jornal Público em maio de 2011. É um poema que, seguindo a linha tomada por Adília nos seus últimos livros, e sobretudo no Apanhar ar, apresenta uma escrita que reflete sobre os instantes banais da vida comum. Neste caso, o poema incorpora totalmente a ideia do registo diarístico, explicitando datas e relacionando-as a pequenos acontecimentos do cotidiano.

\author{
1 de Abril de 2011, $6^{a}$ feira \\ Vi um cão abandonado. \\ 2 de Abril de 2011, Sábado \\ Vi dois papagaios verdes no alto de um choupo. \\ 3 de Abril de 2011, Domingo \\ Vi uma rosa cor-de-rosa no quintal do 14. \\ 4 de Abril de 2011, 2. ${ }^{\text {a }}$ feira \\ Arrumei o casacão no guarda-fato. \\ 6 de Abril de 2011, 4'-feira \\ A Bé gostava de ter um macaquinho. \\ 9 de Abril de 2011, Sábado \\ Quero escrever frases, tagarelar e dançar. \\ Gosto de Solinho. Ver o barómetro. \\ 10 de Abril de 2011, Domingo \\ Descomplicar. \\ A Leonor tem roupa à janela. (LOPES, 2011, p. 7)
}

Os poemas de Adília estão “datados” não só porque expõem o calendário, mas também porque se remetem à atualidade do sujeito que escreve, tal como referiu Derrida à propósito do Ecce homo nietzschiano. O tempo narrado coincide com o momento da escrita ${ }^{6}$ (mesmo quando memória) o que reforça a ideia de autenticidade:

Dater, c'est signer. Et «dater de», c'est aussi indiquer le lieu de la signature. Cette page est en quelque sorte datée puisqu'elle dit «aujourd'hui» et aujourd'hui mon «anniversaire». L'anniversaire, c'est l'instant où l'année tourne sur elle-même, forme avec elle-même un anneau, s'annule et recommence.” (DERRIDA, 1984, p. 53)

E, nesse sentido, reportamos-nos aos poemas de Adília que trazem uma referência à idade. Em alguns deles, um confronto entre os dados biográficos da autora e as datas de publicação dos poemas comprova a existência de um vínculo autobiográfico. Em Clube da poetisa morta, publicado em 1997, lê-se, em uma estrofe do poema “OP-ART": “Tenho 32 anos/ nunca fui a um enterro/ e também nunca fui/ ao Algarve" (LOPES, 1997, p. 293). E em diversas situações de entrevista (ou mesmo em suas crônicas), Adília Lopes declarou ter nascido no ano de 1960. Ora, basta fazer as contas para verificarmos a existência de uma quase linearidade entre os poemas e a biografia da autora.

\footnotetext{
${ }^{6}$ É interessante também notar que o poema interage com o próprio meio em que foi publicado, transformando em notícia uma série de banalidades que comumente não são vistas como dignas de serem noticiadas. Nesse sentido, Adília Lopes aproxima-se do registro poético de Irene Lisboa, que também através de um olhar apurado sobre o banal, convocava uma atenção e um "deslumbramento" diante do cotidiano, o que acabava por provocar uma indiscernibilidade entre a prosa e a poesia - de tal modo que esta autora tenha afirmado na abertura de Outono Havias de Vir Latente Triste: "Ao que vos parecer verso chamai verso e ao resto chamai prosa" (LISBOA 1991: 284).
} 
Podemos constatar a mesma relação quando lemos, no primeiro verso de um poema de O Marquês de Chamilly (kabale und liebe), livo no qual a autora adota a persona da freira Marianna Alcoforado, publicado pela primeira vez em 1987: "Marianna faz vinte e oito anos" ( p. 78).

É escrevendo, e através de seus múltiplos sujeitos-máscaras-personagens que Adilia fala a respeito de seus dias, da sua idade, dos gatos, da tia Paulina, da rua onde mora. Através da apresentação da "história" de uma vida como feita de uma constelação de ínfimas coisas e através de uma memória que é, sobretudo, um arquivo artístico, a poesia de Adilia inscreve no tempo cronológico a possibilidade de experimentação de outra dimensão do tempo: "Vivo/ no instante/ casa/ da eternidade" (LOPES, 2006, p. 594). A autora dá a ver que o tempo da vida e da escrita podem vir a se encontrar, pois são ambos tempos de instantânea e eterna remodelação. Mas, para isso, essa poesia partirá do tempo esquadriado em dias, horas, minutos tal como normalmente o vivemos. A escrita de uma vida surgirá, assim, arranbando o esquema teleológico de uma pessoa que conta os dias num tempo sucessivamente organizado.

A personagem Adilia irá contorcer o interior da temporalidade cronológica para a partir dela inventar uma vida "fora da cronologia", que pode ser "lida em todos os sentidos", conforme nos traz a noção de figura barthesiana. É ainda Roland Barthes que esclarece, em "Durante muito tempo fui dormir cedo", debruçando-se sobre a obra proustiana: "Essa desorganização da biografia não é a sua destruição. Na obra, numerosos elementos da vida pessoal são conservados, de maneira identificável, mas esses elementos estão de certo modo desviados” (BARTHES, 1987, p. 245). Barthes indicará que um desses desvios será o de uma nova consistência do "eu", que "não é aquele que se lembra, se confia, se confessa; é aquele que enuncia; quem é posto em cena por esse "eu” é um "eu” de escritura, cujas ligações com o "eu” civil são incertas, deslocadas" (ibidem).

Em paralelo a essa ideia, Barthes, em "Deliberação" - ensaio no qual se interroga acerca da "utilidade" de escrever (e publicar) um diário -, afirmará que este estará condenado a uma dupla simulação: o diário basear-se-á na forma "antecedente e imóvel” do diário íntimo, que por sua vez ancorar-se-á na representação da emoção, a qual por si já é "cópia da mesma emoção que se leu em algum lugar". Para Barthes, "relatar um humor na linguagem codificada da Lista de Humores é copiar uma cópia; mesmo que o texto fosse «original», já seria uma cópia” (ibidem: 304). Haveria assim no "eu" do diário uma sobrecodificação: a representação de uma intimidade em cima de uma intimidade que já seria resultado de uma representação. Ou seja, as memórias e os sentimentos transpostos para a escrita seriam já previamente delineados pelas memórias e sentimentos compartilhados culturalmente; estes por sua vez, seriam colhidos e retrabalhados pelas memórias e sentimentos do escritor (devedor e sucessor da cultura da qual faz parte).

Será, pois, através da apropriação e da torção da tradição que Adília Lopes, na escrita dos seus dias e das suas memórias, sublinhará as fraturas existentes na subjetividade (empírica e textual). A 
percepção de que a manifestação da emoção - e, duplamente, da emoção corporificada em texto - seria "pescada" de uma "Lista de Humores" já antes ditos e escritos pelos discursos e pela cultura, leva Adília ao desejo de fazer transbordar a vida do texto no texto da vida. Pensar na vida como processo de feitura, permite esperar que texto e vida possam coincidir: "Eu sou a luva/ e a mão/ Adília e eu/ quero coincidir/ comigo mesma (LOPES, 1999, p. 337). O "eu" diarístico, quando tornado personagem/figura da escrita, foge da sua determinação, descola-se da identidade de um referente. Artifício e realidade coexistem. Em $O$ decote da dama de espadas (1988), publicado quase dez anos antes do livro do qual transcrevemos o poema anterior, lê-se:

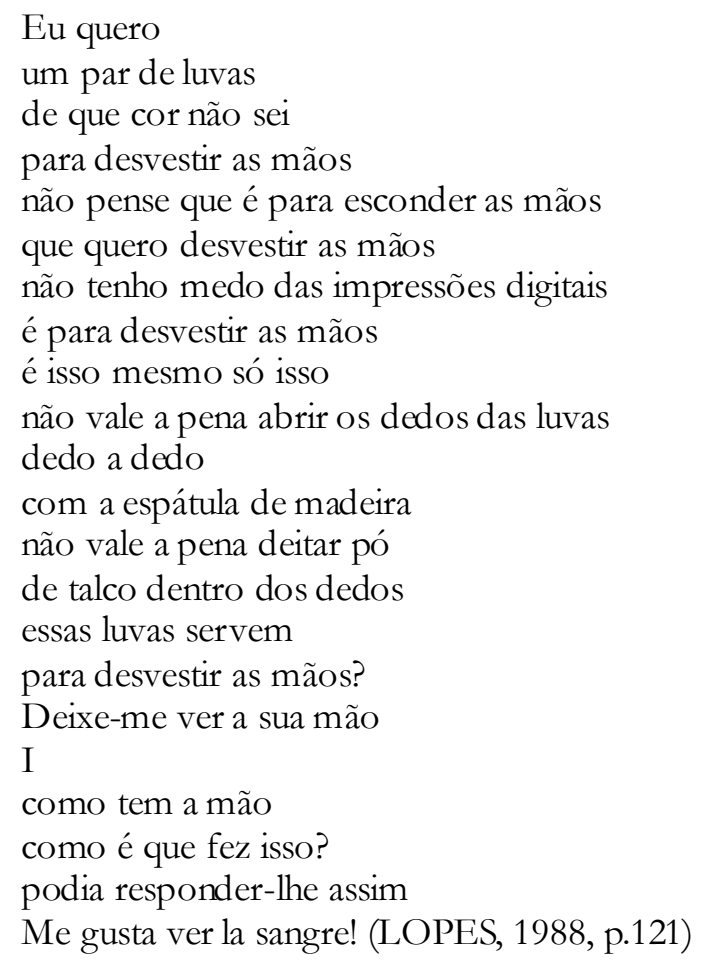

O artifício da subjetivação poética não será um meio no qual a poetisa tematizará obliquamente os sentimentos, mas passa a ser visto como veículo para que a subjetividade possa apresentar-se tal como é: em devir. Adília “não tem medo das impressões digitais". Quanto mais sincero é o poeta mais vestido estará de artificio. E, da mesma forma, o inverso: quanto mais vestido do artifício poético, mais sincero poderá vir a ser o poeta. Equilibrando-se na instabilidade entre a verdade e a simulação (e a simulação como verdade, e a verdade como simulação...), o público e o privado, o literário e o não-literário, os poemas adilianos reelaborarão as questões em torno da subjetividade poética da modernidade.

Ao final do poema, lemos: "me gusta ver la sangre". Adília faz questão de realçar a transfusão entre o corpo do autor e o corpo do texto. Deseja ser "a luva e a mão", propõe-se a encarnar o artifício poético. 


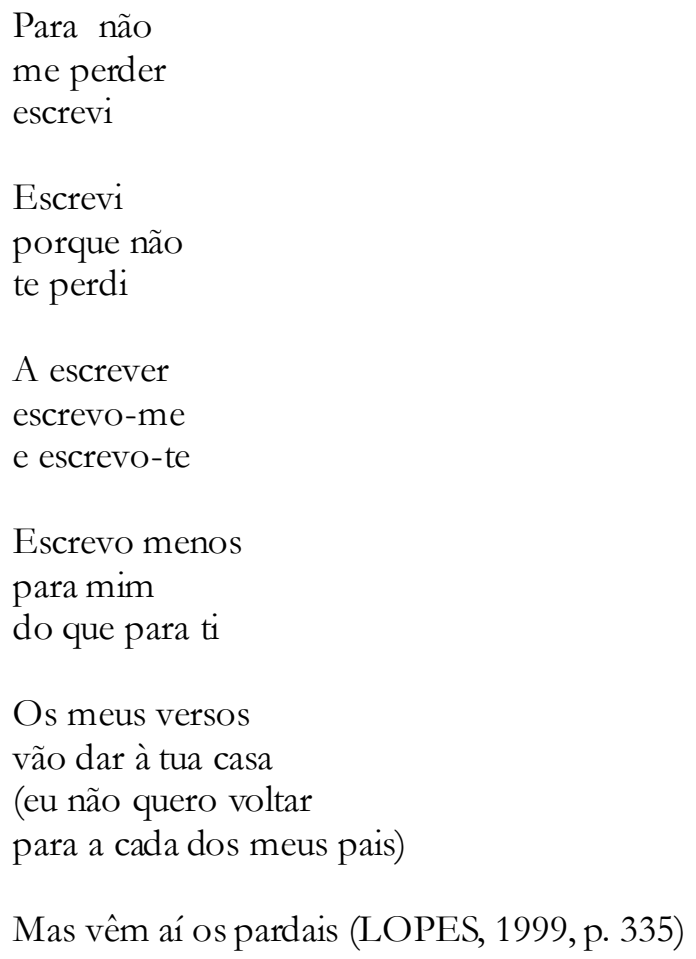

A vida é colocada como espaço de convívio - entre o leitor e o autor, entre o sujeito textual e o empírico e, ainda, em relação a uma subjetividade em processo (o que o sujeito pode vir a ser). No poema, há um sucessivo desprendimento do "eu": o sujeito escreve para não se perder; escreve para o outro; escreve para escrever a si e ao outro; escreve mais para o outro do que para si; escreve por não querer voltar a um espaço identitário "familiar" e por fim... lá estão os pardais, por mera questão de rima. O "voar outro" pessoano se complexifica, podendo ser lido não apenas sob o foco da encenação, mas na percepção de que o sujeito é, em si, multifacetado. Em entrevista para a Revista Inimigo Rumor, n 20 , Adília Lopes irá declarar: "Nunca me desdobro, isto é, não me vejo a escrever. Nada tenho a ver com Pessoa. Enfim, todos depois de Pessoa têm a ver com Pessoa. Mas o duplo não me interessa" (LOPES, 2008, p. 99). O não interesse de Adília Lopes pelo mecanismo de alterização poética pessoano não significará que a poesia da autora será feita no mais absoluto derramamento lírico - as inúmeras máscaras que usa são prova disso. Tendo a ver com Pessoa, como todos, depois do poeta, têm a ver com ele, Adília Lopes perceberá a identidade do sujeito poético como uma identidade sempre em devir. A marca da poesia adiliana estará, na verdade, em fundir o sujeito lírico à pessoa de carne e osso, apresentando ambos em aberto. A figuração de uma identidade (lírica e subjetiva) não virá, pois, através de uma afirmação, mas de uma pergunta; como Barthes concluirá acerca daquele que escreve o diário:

No fundo, todos esses desfalecimentos do sujeito designam bastante bem certa falha do sujeito. Essa falha é a existência. O que o Diário levanta, não é questão trágica, a questão do Louco: "Quem sou?", mas a questão cômica, a questão do Pasmado: "Sou?”. Um cômico, eis o que é o autor de Diário." (BARTHES, 1987: p. 312)

Em "Out of the past", Adília escreve: "Preciso que/ me reconheçam/ que me digam Olá/ e 
Bom dia/ mais que de espelhos/ preciso dos outros/ para saber/ que eu sou eu" (LOPES 1999: 345). E na mesma obra dirá: "A minha vida/ foi um mau sonho/ mas agora é minha/ eu sou eu" (ibidem: 385). E em Le vitrail la nuit * A árvore cortada: "Um espelho/ não é/ uma janela// Um espelho/ não é/ um quadro// Quem espreita/ por meus olhos/ no espelho/ sou eu// E eu/ sou eu// Não há/ enigmas" (idem 2006: 580). A sentença "eu sou eu"” que forja a solução do enigma, na verdade, apronfunda-o. Os dois pólos de uma possível estabilização de identidade surgem sem referente de estabilização. E eis a grande ironia do intimismo de Adília Lopes: ao mesmo tempo em que se apresenta em tamanha evidência, o lugar do sujeito se desloca infinitamente, reverberando no vazio da sua indeterminação. Em "eu sou eu", sujeito e predicado têm igual valor. O que fica entre eles é o "sou": a subjetividade dobra-se ironicamente sobre si mesma, desloca a pergunta de "quem é o sujeito?", para a inquirição a respeito do seu próprio modo de existência. "Nela [Adília Lopes], o sujeito é de tal modo uma ficção que sente a necessidade de proclamar, como na portada de Florbela espanca espanca, que 'Este livro/ foi escrito/ por mim"” (SILVESTRE, 2001, s/p).

E, aqui, acreditamos ser produtivo convocar as ideias de Paul de Man quando, em "A Retórica da Temporalidade", problematiza a noção de dédoublement da ironia baudelairiana - a ironia definida a partir de um sujeito duplicado em si mesmo: "la puissance d'être à la fois soi et un autre " (BAUDELAIRE apud DE MAN 1999, p. 232). Em diálogo com a ideia de dédoublement da ironia baudelairiana, Paul de Man afirmará que "[a] natureza desta duplicação é essencial a uma compreensão da ironia. Trata-se de uma relação, no interior da consciência, entre dois eus, e, no entanto, não é uma relação intersubjectiva" (DE MAN, 1999, p. 232). É uma relação isenta de poder, pois já não há uma pessoa que ri da outra, mas a fissura do próprio sujeito que se desdobra em objeto de riso. E essa duplicação será somente possível "por meio" de uma linguagem, através da sua prevalência, do seu uso enquanto matéria e não instrumento. Será, pois, um trabalho ironista da linguagem que dividirá “o sujeito entre um eu empírico, imerso no mundo, e um eu que se torna como que num signo através da sua tentativa de se diferenciar e auto-definir" (ibidem, p. 234). E mais adiante, diz ainda Paul de Man:

A linguagem irónica cinde o sujeito num eu empírico que existe num estado de inautenticidade e num eu que existe apenas sob a forma de uma linguagem que afirma o conhecimento desta inautenticidade. Isso não a torna, no entanto, uma linguagem autêntica, visto que reconhecer a inautenticidade não é o mesmo que ser autêntico" (ibidem, p. 234, 235)

$\mathrm{Na}$ formulação "eu sou eu" adiliana, os dois lados em que a subjetividade se projeta - o empírico e o textual - reconhecem a inautenticidade em afirmar uma identidade. "As osgas têm um eu? As plantas têm um eu apesar de não terem cérebro? E as pedras?”, questiona Adilia, num texto de Irmã

\footnotetext{
7 Esta constru ção será uma constante da poesia adiliana. Podemos en contrá-la, por exemplo, em Irmã barata, irmã batata (2000) - "Eu sou eu e a minha circunstân cia como disse Julio Iglesias" (LOPES 2000 [2009], p.421) - ou ainda no poema "Poetis a-Fêmea, Po eta-Macho" de Mulher-a-dias (2002) - "Eu estou nua/ eu estou viva/ eu sou eu" (LOPES 2002 [2009], p. 463).
} 
barata, irmã batata, que tem como sequência e desfecho: “O eu, um eu, o meu eu precisa de luz e de escuridão" (LOPES, 2002, p. 417). Ao mesmo tempo em que se revela, o "eu" se apaga, se inquirindo dentro da própria afirmação. É, pois, ironicamente que Adilia o define - "Pateta, patética, peripatética: eu" (ibidem, p. 421).

Comicidade da poesia de Adília Lopes: buscar uma definição de Adillia Lopes. Um pseudônimo? Um heterônimo poético? Uma pessoa de "verdade"? Em qualquer um dos casos - e transitando em todos eles - essa poesia fala daquilo que não sabe, sabendo que não o sabe e deixando à mostra que não o sabe.

Loucura da poesia de Adilia Lopes: inventar "formas" de Adília Lopes. Ou como diria Paul de Man: “(...) o ironista inventa uma forma de si próprio que é "louca” mas que desconhece a sua própria loucura; reflete sobre a sua loucura dessa forma objetivada” (DE MAN, 1999, p. 237). E é um louco sem previsão de cura. Pois, conforme alerta o autor, seria uma distorção da própria ironia, essa "folie lucide", percebê-la como "cura" do sujeito empírico através do textual. Perceber a ironia como "uma espécie de terapia, uma cura para a loucura através da palavra falada ou escrita" (DE MAN, 1999, p. 237) seria esgotá-la mesmo na sua fonte - já que essa se fará na inquirição desde dentro da própria estabilidade do sujeito a partir da linguagem que o representa. A comicidade ou a loucura do sujeito irônico estaria justamente em sua incessante não reconciliação com o mundo; na "defe[sa] e man[utenção] [d]o seu carácter ficcional afirmando a impossibilidade continuada de reconciliar o mundo da ficção com o mundo real" (ibidem, p. 238). Estaria, pois, numa busca da definição de si em que "o eu” volta-se contra si mesmo ironicamente.

Sou mulher
sou colher
sou boca
sou nova
sou velha
sou mãe
sou irmã
sou cristã
sou tua
sou minha
ai alminhas
ai maminhas
Santa Teresinha
do Menino Jesus
doutora da Igreja
Santa Teresa
de Jesus
doutora da Igreja
utopias de Charles Fourier
harmonias de Joseph Fourier (LOPES, 1999, 367)

A repetição do "sou" converte-se numa ladainha religiosa - busca uma religação com uma 
identidade (uma transcendência que possa garantir a estabilidade do sujeito). Porém, como resultado dessa busca, só temos palavras, e as aproximações sonoras e semânticas entre umas e outras. Daí partirá a constância (por vir) do sujeito. Ele - tal como as orações, as utopias e as harmonias - mostrar-se-á produto do discurso, objeto de invenção. Ao contrário de uma identidade como constância, que se repetirá sucessivamente, Adilia propõe - através da inquirição desde dentro da linguagem - que as constantes do sujeito nada mais são que a repetição de uma infinidade de traços aleatórios que, todavia, se organizam e se agrupam entre si, estabelecendo, assim, a sua (frágil) unidade. Por essa via, as repetições e as duplicações - que aparecem sistematicamente na poesia adiliana - poderão ser vistas como um dos processos pelos quais a autora cria os deslocamentos entre o sujeito textual e o sujeito empírico e coloca em questão a formulação causa-efeito da escrita de vida.

Regressando a Paul de Man, podemos perceber as duplicações adilianas (duplicações irônicas, pois cindem o sujeito que passa a questionar "sou?" - tal qual o "pasmado" barthesiano) como desarticulação de um tempo conduzido rumo a uma finalidade. A esse respeito, Paul de Man afirmará:

O acto da ironia, como agora o entendemos, revela a existência de uma temporalidade que definitivamente não é orgânica, na medida em que se relaciona com a sua fonte apenas em termos de distância e de diferença e não permite fim algum, totalidade alguma. A ironia divide o fluxo da experiência temporal num passado que é pura mistificação e num futuro que permanece para sempre assediado pela possibilidade de uma queda no inautêntico. (DE MAN, 1999, p. 243)

Por essa via, ainda que sustente um pacto referencial, através do registo autobiográfico e diarístico, Adília Lopes nunca poderá estabelecer com esses gêneros uma zona de constante conforto, pois, vários traços que são inerentes a esses gêneros serão subvertidos. O “diário” de Adilia só poderá ser um diário irônico, que ri da existência de si mesmo. Se há uma lógica da autenticidade, ela será desarticulada por se fazer em torno de um nome inventado que se define por meio de uma série de personagens e pontos de vista que, muitas vezes, nem chegam a ser humanos. Se há um pacto de veracidade, através de um universo reconhecível e verificável empiricamente, esse é quebrado pelo uso de uma linguagem que recai sobre si mesma, pondo-se sempre em dúvida. Se há uma vida contada na simulação de uma sucessividade, ela o faz de forma não linear, suspendendo o tempo para o plano do instante do acontecimento. E assim é por um simples fato: o que Adília se propõe fazer - e faz - é poesia.

\section{BIBLIOGRAFIA}

BAPTISTA, Abel Barros, "O espelho perguntador. Sobre crónicas e diários”, Coligação de avulsos. Ensaios de crítica literária, Lisboa, Cotovia, p.13-48, 2003.

BARTHES, Roland, O rumor da lingua (or. Le Bruissement de la Langue, 1984), trad. António Gonçalves, Lisboa, Edições 70, 1987.

, S/Z, trad. Maria de Santa Cruz e Ana Mafalda Leite, Lisboa, Edições 70, 1999.

BLANCHOT, Maurice, O livro por vir, trad. Leyla Perrone-Moisés, São Paulo, Martins Fontes, 2005. 
DE MAN, Paul, "Autobiography as De-Facement", The rhetoric of romanticism, New York, Columbia University Press, p. 67-8, 1984.

, O ponto de vista da cegueira. Ensaios sobre a retórica da crítica contemporânea, trad. Miguel Tamen,

Coimbra/Lisboa, Angelus Novus/Cotovia, 1999.

DERRIDA, Jacques, Otobiographies. L'enseignement de Nietzsche et la politique du nom prope, Paris, Galilée, 1984.

DIOGO, Américo António Lindeza, "Poemas com pessoa", in: LOPES, Adília, O poeta de Pondichéry seguido de Maria Cristina Martins, Braga/Coimbra, Angelus Novus.

LISBOA, Irene, Poesia I - Um dia e outro dias e Outono havias de vir, Lisboa, Presença, 1991.

LOPES, Adilia, O Marquês de Chamilly (kabale und liebe), Lisboa, Hiena, 1987; ed. ut: Dobra: Poesia Reunida, Lisboa, Assírio \& Alvim, 2009.

O decote da dama de espadas (romances), Lisboa, Gota de Água/Imprensa Nacional, 1988; ed. ut: Dobra: Poesia Reunida, Lisboa, Assírio \& Alvim, 2009.

, Clube da poetisa morta, Lisboa, Black Sun, 1997; ed. ut: Dobra: Poesia Reunida, Lisboa, Assírio \&

Alvim, 2009.

, Sete rios entre campos, Lisboa, \& etc, 1999; ed. ut: Dobra: Poesia Reunida, Lisboa, Assírio

$\&$

Alvim, 2009.

, Florbela espanca espanca, Lisboa, \&etc, 1999; ed. ut: Dobra: Poesia Reunida, Lisboa, Assírio \& Alvim,

2009

, Irmã barata, irmã batata, Braga-Coimbra, Angelus Novus, 2000; ed. ut: Dobra: Poesia Reunida, Lisboa, Assírio \& Alvim, 2009.

, A mulher-a-dias, Lisboa, \& etc, 2002; ed. ut: Dobra: Poesia Reunida, Lisboa, Assírio \& Alvim, 2009.

, Poemas novos, Lisboa, \& etc, 2004; ed. ut: Dobra: Poesia Reunida, Lisboa, Assírio \& Alvim,

2009.

, Le vitrail la muit * A árvore cortada, Lisboa, \&etc, 2006; ed. ut: Dobra: Poesia Reunida, Lisboa, Assírio \& Alvim, 2009.

, Caderno, Lisboa, \& etc, 2007; ed. ut: Dobra: Poesia Reunida, Lisboa, Assírio \& Alvim, 2009.

, Dobra: poesia reunida [inclui Os namorados pobres], Lisboa, Assírio \& Alvim, 2009.

, Apanhar ar, Lisboa, Assírio \& Alvim, 2010.

"Diário Lisboeta", Público, Sábado, 21 de maio de 2011, p.7, 2011.

, "Como se faz um poema?" [resposta a um inquérito], Inimigo rumor: revista de poesia - Edição

Especial: 10 anos de Inimigo rumor, no 20, Rio de Janeiro e São Paulo, 7 Letras e Cosac Naify, p. 109-110, [publicado originalmente em Relâmpago, no 14, Fundação Luís Miguel Nava, Lisboa, Relógio D’Água, p. 29-30]

LOPES, Adilia/ SILVESTRE, Osvaldo e DIOGO, Américo Lindeza, "Entrevista com Adilia Lopes", Inimigo rumor: Revista de poesia, n 10, Rio de Janeiro, 7 Letras, p. 18-23, 2001.

LOPES, Adília/ CORTEZ, António e MESTRE, Marta, “Adília Lopes: uma anã aos ombros do gigante”, Rodapé: Revista da Biblioteca Municipal de Beja José Saramago, no 4, p. 6-9, 2001.

LOPES, Adilia/ PEDROSA, Celia, "Entrevista de Adilia Lopes", in: Inimigo rumor: Revista de poesia - Edição Especial: 10 anos de Inimigo Rumor, no 20, Rio de Janeiro/São Paulo, 7Letras/Cosac Naify, p. 96-108, 2008. 
Revista .

SILVESTRE, Osvaldo Manuel, "Adilia Lopes espanca Florbela Espanca”. Inimigo rumor: Revista de poesia, no 10, Rio de Janeiro, 7 letras, maio 2001.

Artigo recebido em 30 de Março de 2012 e aprovado em 11 de Maio de 2012 